\title{
In vitro Plant Regeneration from Leaf Explants of Artemisia vulgaris L. - A Medicinal Herb
}

\author{
Rezvan Karami Borzabad(Corresponding author), Mysore Shankarsingh Sudarshana \& Mallappa Hanumanthu \\ Niranjan \\ Medicinal Plant Tissue Culture Laboratory, Department of studies in Botany, Manasagangotri \\ University of Mysore, Mysore-570006, Karnataka, India \\ E-mail: r_karami61@yahoo.com
}

\begin{abstract}
A reliable protocol for callus induction and regeneration were developed for leaf explants of Artemisia vulgaris L. Percent of callus induction and regeneration were higher in the young leaves. MS medium containing 1.0 $\mathrm{mgl}^{-1} \mathrm{BAP}$ and $3.0 \mathrm{mgl}^{-1} \mathrm{NAA}$ is the optimum concentration for induction of callus. So produced callus was subcultured on Murashige - Skoog (MS) medium with $1.0 \mathrm{mgl}^{-1}$ 6-benzylaminopurine (BAP), $3.0 \mathrm{mgl}^{-1}$ gibberellic acid $\left(\mathrm{GA}_{3}\right)$ produced the highest mean number of shoots $(35.85 \pm 0.81)$ per explant. Half strength of MS was found to be the best for rooting, however, addition of IAA $\left(0.5-1.0 \mathrm{mgl}^{-1}\right)$ was found essential to induce longer roots. More than $84 \%$ of the rooted plants were established in polycups after hardening.
\end{abstract}

Keywords: Callus induction, Plant regeneration, Leaf explants, Artemisia vulgaris L

\section{Introduction}

Artemisia vulgaris Linn, an important perennial medicinal herb belongs to the family Asteraceae. The plant is aromatic, shrubby $0.6-2.4 \mathrm{~m}$ high and pubescent. The plant has a hot, sharp and pungent taste. It is considered to be a valuable stomachic, deobstruent and antispasmodic. The expressed juice is used in diseases of children. The leaves and shoot tips are administered in nervous and spasmodic affections connected with debility, in asthma and diseases of the brain. It shows antispasmodic and anthelmintic activity(Kirtiker and Basu, 1935).

Leaf explants have been employed for regeneration by many researchers observed in Centaurreum erythraea (Baresova et al., 1985); Jatropha integerrima (Sujatha and Dhingra,1993); Solanum pseudocapsicanum (Baburaj and Gunasekaran, 1994); Guizotia abssinica (Jadimath, 1998); Jatropha curcus (Sardana et al. ,2000). The present study describes an optimized regeneration system in Artemisia vulgaris callus derived from leaf explant cultures on a variety of medium composition.

\section{Materials and methods}

\subsection{Plant material}

Leaf explants from 6-month-old mature plant of Artemisia vulgaris L. were used to initiate in vitro cultures. The leaf segments were washed with $5 \%(\mathrm{w} / \mathrm{v})$ bavistin, $10 \%(\mathrm{w} / \mathrm{v})$ antibiotic and $5 \%(\mathrm{w} / \mathrm{v})$ Tween 20 by continuous shaking for $20 \mathrm{~min}$ followed by washing in tap water, then rinsed three to five times with double distilled water.

\subsection{Callus induction}

To induce callus, the sterile leaf explants were inoculated on MS Medium, containing BAP (0.5-1.0 mgl $\left.{ }^{-1}\right)$ and NAA $\left(0.5-3.0 \mathrm{mgl}^{-1}\right), 0.8 \%(\mathrm{w} / \mathrm{v})$ agar as gelling agent and $30 \%(\mathrm{w} / \mathrm{v})$ sucrose. The $\mathrm{p}^{\mathrm{H}}$ of the medium was adjusted to 5.8 before autoclaving, a light intensity of $10 \mu \mathrm{mol} \mathrm{m} \mathrm{m}^{-2} \mathrm{~s}^{-1}$ (cool white fluorescent light) and a temperature of $25 \pm 2^{0} \mathrm{C}$.

\subsection{Shoot induction and elongation}

Shoots were induced by transferring the leaf calli on MS medium containing different concentrations and combinations of BAP $\left(0.5-1.0 \mathrm{mgl}^{-1}\right)$ and $\mathrm{GA}_{3}\left(0.5-3.0 \mathrm{mgl}^{-1}\right)$. Elongation of shoots were also observed on the same medium.

\subsection{Rooting and Acclimatization}

Microshoots were excised from the parent cultures and transferred onto half strength MS medium supplemented with different concentrations and combinations of IBA, IAA and NAA for root induction. The rooted shoots were gently removed from the culture vessels, washed under running tap water and transferred to polycups containing sand:soil:vermiculite $(1: 1: 1)$ in the greenhouse conditions for acclimatization. 


\section{Results and discussion}

\subsection{Callus induction}

To induce callus from leaf explants, they were inoculated on MS medium containing $0.5-1.0 \mathrm{mgl}^{-1} \mathrm{BAP}$ and 0.5-3.0 $\mathrm{mgl}^{-1} \mathrm{NAA}($ Table $1 \&$ Fig 1.A). Among the various concentrations and combinations highest (81\%) callus was achieved on MS medium supplemented with BAP $\left(1.0 \mathrm{mgl}^{-1}\right)$ and NAA $\left(3.0 \mathrm{mgl}^{-1}\right)$. Young leaves have been proved to be callus in other plant species, such callus potential has been reported to vary from species to species and often differs in varieties of same species (Vasil, 1982). Similar observations have been reported in Jatropha integerrima (Sujatha and Dhingra, 1993); Jatropha curcus ( Sujatha and Mukta, 1996); Solanum tuberosum (Jayasree et al., 2001); Solanum torvum (Jaseela and Nair, 2004); Rauwolfia micrantha (Vishwanath et al., 1997); Rauwolfia serpentina (Nishi Koshta et al., and Anitha et al., 2002).Combinations of BAP and NAA have been used for regeneration by many investigators.

\subsection{Shoot induction and elongation}

Shoots from callus was observed at different concentrations of 0.5-1.0 mgl- ${ }^{-1} \mathrm{BAP}$ and $0.5-3.0 \mathrm{mgl}^{-1} \mathrm{GA}_{3}$ (Fig.1B). The best shoot induction $(35.85 \pm 0.81)$ per explant for leaf was observed on BAP $\left(1.0 \mathrm{mgl}^{-1}\right)$ in combination with $\mathrm{GA}_{3}\left(3.0 \mathrm{mgl}^{-1}\right)$. The elongation of shoots were achieved $(4.11 \pm 0.85)$ on the same medium (Table $2 \&$ Fig. $\left.1 \mathrm{C}\right)$.

Combination of $B A P$ and $G A_{3}$

The effect of $\mathrm{GA}_{3}$ on the embryogenic frequency became significant after two weeks in the induction medium and caused a noticeable rise in the intensity and number of embryos and shoots in Artemisia vulgaris. There are many reports that $\mathrm{GA}_{3}$ enhances the number of somatic embryos and shoots from the calli of Santalum album $\mathrm{L}$. (Lakshmi et al., 1979); Rumex acetosella L. (Culafic et al., 1987); Mentha piperita (Ghanti et al., 2004) and Phyllanthus amarus (Chitra et al., 2009),

\subsection{Rooting and Acclimatization}

The shoots formed in the calli derived from leaf segments were transferred onto half strength MS medium supplemented with different concentrations and combinations of IAA, NAA and IBA for root induction. Data were recorded for percentage of shoots forming roots, number of roots/shoots and root length. Root induction occurred in 10-12 days of culturing with highest root induction (87\%) on MS medium containing $0.5 \mathrm{mgl}^{-1}$ (IAA) (Table3 \& Fig.1D). Root formed in IAA were thick, long and white. The role of IAA as an effective root inducing auxin had also been in Amygdalus communis L. (Akbas et al., 2009) and Centaurium erythraea (Piatczak and Wysokinska, 2003).

The plantlets having sufficient root and shoot system were taken out from the culture vessels and were washed under running tap water to remove the agar attached to shoots. The plantlets were transferred to polycups (Fig.1E) containing autoclaved sand: soil: vermiculite (1:1:1) mixture in the greenhouse condition. They were transferred to the field condition.

In conclusion, the above protocol describes rapid callus induction from leaf explants, which can ensure a stable supply of this medicinally oil yielding plant irrespective of any seasonal variation and may serve as a better source for biological active compounds.

\section{References}

Akbas, F.; Isikalan, C.; Namli, S., and AK E. B. (2009). Effect of plant growth regulators on in vitro shoot multiplication of Amygdalus communis L. c.v.Yaltsinki. African J. Biotech. 8(22), 6168-6174.

Anith, R. S.; Sanjogta, U. and Chowdhury, J. B. (2002). Establishment of plantlets and evaluation of differentiated roots for Alkaloids in Rauwolfia serpentina. Journal of Plant Biochm. \& Biotech. 11,105-108.

Baburaj, S. and Gunasekaran, K. (1994). Regeneration of plants from leaf callus culture of Solanum pseudocapsicanum L. Indian J. Exp. Biol. 32,141-143.

Baresova, H.; Herben, T.; Kaminek, M. and Krekule, J. (1985). Hormonal control of morphogenesis in leaf segments of Centaureum erythraea. Biol. Plant. 27, 286-291.

Chaturvedi, H.C. (1975). Propagation of Dioscorea floribunda from in vitro culture of single node stem segments. Curr. Sci. 44, 839-841.

Chitra, R.; Rajamani, K. and Vadivel, E. (2009). Regeneration of plantlets from leaf and internode explants of Phyllanthus amarus Schum. and Thonn. African J. Biotech. 8(10),2209-2211. 
Culafic, L.; Budirmir, S.; Vajicic, R. and Neskovic, M. (1987). Induction of somatic embryogenesis and embryo development of Rumex acetosella L. Plant Cell Tiss. Organ Cult. 11,133-139.

Ghanti, K.; Kaviraj, C.P.; Venugopal, R.B.; Jabeen, F.T.Z. and Rao, S. (2004). Rapid regeneration of Mentha piperita L. from shoot tip and nodal explants. Indian J. Biotech. 3,594-598.

Jadimath, V. G.; Murthy, H. N.; Pyati, A. N.; Kumar, H.G.A. and Ravishankar, B. V. (1998). Plant regeneration from leaf cultures of Guizotia abssinica (Nigar) and Guizotia scabra. Phytomorph. 48(2), 131-135.

Jaseela, F. and Nair, G. N. (2004). Plantlet regeneration from leaf and leaf derived callus of Solanum torvum Swartz. J. Cytol. Genet. 5(NS), 33-37.

Jayashree, T.; Pavan, U.; Ramesh, A.V.; Rao. K.; Jagan, M.R. and Sadanandan, A. (2001). Somatic embryogenesis from leaf cultures of potato (Solanum tuberosum). Plant Cell Tissue and Organ Culture. 64,13-17.

Kirtikar, K.R. and Basu, B.D. (1935). Indian Medicinal plants. $2^{\text {nd }}$ edition Vol II. International book distributors. pp. 1395-1396.

Lakshmi, S.G.; Rhagava, R.N.V. and Vaidyanathan, C.S. (1979). Differentiation of embryoids and plantlets from shoot callus of Santalum album. Pt. Sci. Lett. 15, 265-270.

Nishi, K. and Bansal, Y.K. (2002). Shoot tip culture for Micropropagation of medicinal plant sarpagandha (Rauwolia serpentina Benth Excurz. J. Physiol. Res. 15(1), 95-99.

Piatczak, E. Wysokinska, H. (2003). In vitro regeneration of Centaurium erythraea Rafn from shoot tips and other seedling explants. Acta. Societatis Botanicorum poloniae. 72(4), 283-288.

Sardana, J.; Bara, A. and Ali, D.J. (2000). An expeditious method for regeneration of somatic embryos in Jatropha curcus L. Phytomorph. 50(3,4), 239-242.

Sujatha, M. and Dhingra, M. (1993). Rapid plant regeneration from various explants of Jatropha integerrima. Plant Cell Tissue and Organ Culture. 35, 293-296.

Sujatha, M. and Mukta, N. (1996). Morphogenesis and plant regeneration from cultures of Jatropha curcus. Plant Cell Tissue and Organ Culture. 44, 135-141.

Vishwanath, M.P. and Jayanthi, M. (1997). Micropropagation of two species of Rauwolfia (Apocynaceae). Curr. Sci. 72(12): 961-965.

Table 1. Callogenesis from leaf explants of Artemisia vulgaris L. at different concentrations of BAP and NAA.

\begin{tabular}{|c|c|c|c|}
\hline \multicolumn{2}{|c|}{ Growth regulator in $\mathrm{mgl}^{-1}$} & \multirow{2}{*}{ \% of response* } & \% of forming callus \\
\cline { 1 - 2 } BAP & NAA & 25 & $4.00 \pm 0.00$ \\
\hline 0.5 & 0.5 & 26 & $4.00 \pm 0.00$ \\
\hline 0.5 & 1.0 & 31 & $5.00 \pm 0.00$ \\
\hline 0.5 & 1.5 & 44 & $7.00 \pm 0.00$ \\
\hline 0.5 & 2.0 & 50 & $8.00 \pm 0.00$ \\
\hline 0.5 & 2.5 & 56 & $8.85 \pm 0.00$ \\
\hline 0.5 & 3.0 & 35 & $6.00 \pm 0.00$ \\
\hline 1.0 & 0.5 & 44 & $7.00 \pm 0.001$ \\
\hline 1.0 & 1.0 & 56 & $9.00 \pm 0.26$ \\
\hline 1.0 & 1.5 & 68 & $10.90 \pm 0.58$ \\
\hline 1.0 & 2.0 & 75 & $12.00 \pm 0.61$ \\
\hline 1.0 & 2.5 & 81 & $13.00 \pm 0.31$ \\
\hline 1.0 & 3.0 & & \\
\hline
\end{tabular}

*Mean of 12 replicates per treatment in three repeated experiments 
Table 2. Effect of growth regulator on in vitro shoot induction from leaf explants of Artemisia vulgaris L.

\begin{tabular}{|c|c|c|c|c|}
\hline \multicolumn{2}{|c|}{ Growth regulator in $\mathrm{mgl}^{-1}$} & \multirow{2}{*}{$\begin{array}{c}\text { \% of } \\
\text { response }\end{array}$} & No. of shoots/explant* & Shoot length (cm)* \\
\hline BAP & $\mathrm{GA}_{3}$ & 44 & $7.50 \pm 0.51$ & $1.74 \pm 0.15$ \\
\hline 0.5 & 0.5 & 50 & $10.40 \pm 0.50$ & $1.80 \pm 0.07$ \\
\hline 0.5 & 1.0 & 63 & $13.90 \pm 0.85$ & $2.14 \pm 0.12$ \\
\hline 0.5 & 1.5 & 68 & $18.45 \pm 0.51$ & $2.42 \pm 0.16$ \\
\hline 0.5 & 2.0 & 81 & $21.50 \pm 0.51$ & $3.03 \pm 0.10$ \\
\hline 0.5 & 2.5 & 88 & $25.50 \pm 0.51$ & $3.05 \pm 0.10$ \\
\hline 1.0 & 3.0 & 56 & $9.55 \pm 0.51$ & $3.12 \pm 0.69$ \\
\hline 1.0 & 0.5 & 63 & $12.50 \pm 0.51$ & $3.19 \pm 0.26$ \\
\hline 1.0 & 1.0 & 75 & $19.63 \pm 1.11$ & $3.24 \pm 0.05$ \\
\hline 1.0 & 1.5 & 81 & $24.38 \pm 0.92$ & $3.50 \pm 0.08$ \\
\hline 1.0 & 2.0 & 93 & $29.45 \pm 2.39$ & $3.58 \pm 0.08$ \\
\hline 1.0 & 2.5 & 100 & $35.85 \pm 0.81$ & $4.11 \pm 0.85$ \\
\hline
\end{tabular}

* Mean of 12 replicates per treatment in three repeated experiments

Table 3. Effect of different concentrations of IAA on rooting of in vitro shoots of Artemisia vulgaris L.

\begin{tabular}{|c|c|c|c|}
\hline IAA in $\mathrm{mgl}^{-1}$ & $\begin{array}{c}\% \text { of } \\
\text { response* }\end{array}$ & $\begin{array}{c}\text { No. of } \\
\text { roots/shoot* }\end{array}$ & $\begin{array}{c}\text { Root length } \\
(\mathrm{cm})^{*}\end{array}$ \\
\hline 0.5 & 87 & $7.45 \pm 0.59$ & $4.40 \pm 0.26$ \\
\hline 1.0 & 80 & $3.65 \pm 0.50$ & $3.51 \pm 0.08$ \\
\hline 1.5 & 78 & $4.58 \pm 0.58$ & $2.74 \pm 0.34$ \\
\hline 2.0 & 72 & $3.50 \pm .0 .51$ & $2.71 \pm 0.81$ \\
\hline
\end{tabular}

*Mean of 12 replicates per treatment in three repeated experiments 

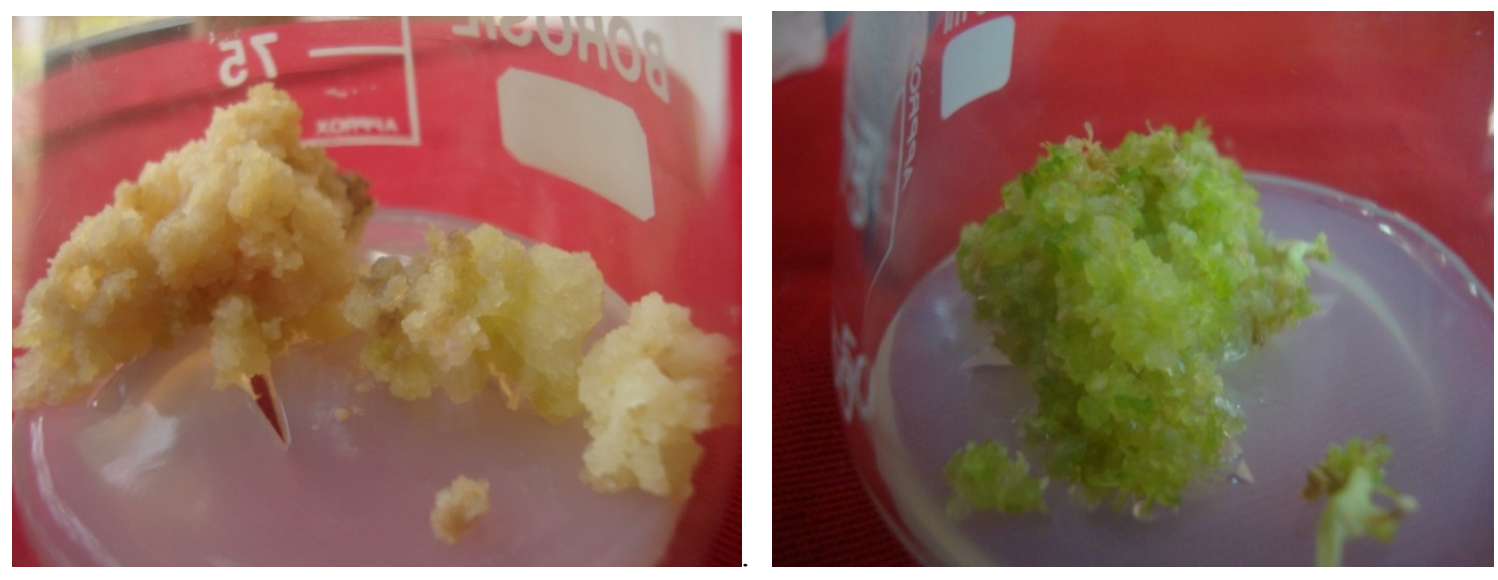

(A)

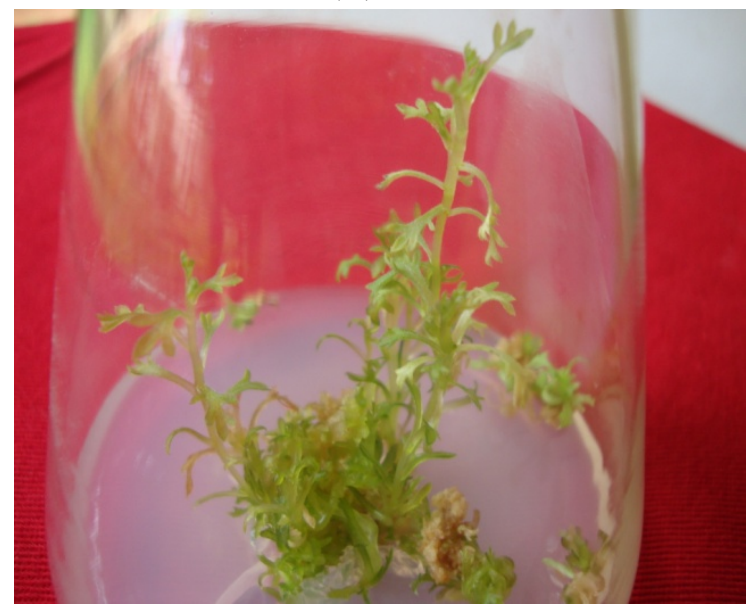

(C)
(B)

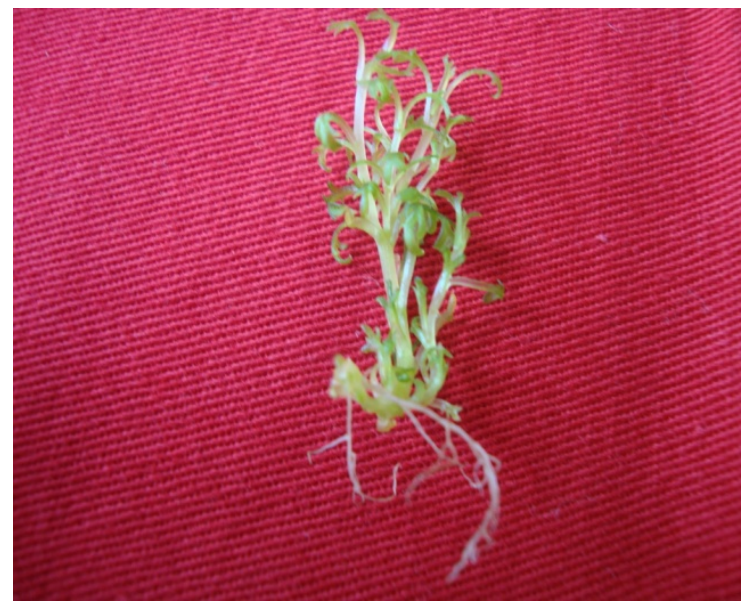

(D)

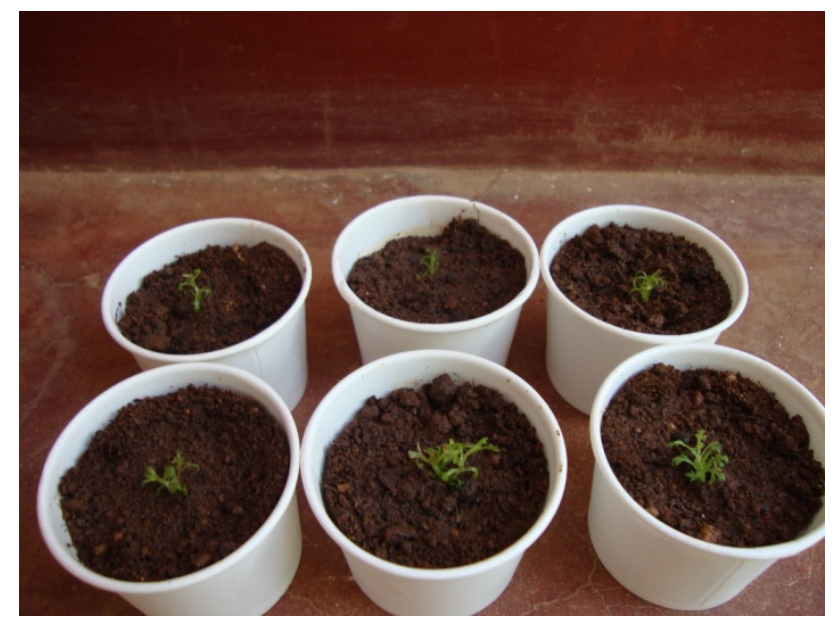

(E)

Figure 1. In vitro plant regeneration from leaf explants of Artemisia vulgaris Linn. (A) Callus induction from leaf explants of Artemisia vulgaris on MS medium containing BAP (1.0 mg/l) +NAA (3.0 mg/l). (B) and (C) Sub-culturing of callus on MS medium supplemented with BAP $(1.0 \mathrm{mg} / 1)$ and $\mathrm{GA}_{3}\left(3.0 \mathrm{mgl}^{-1}\right)$, differentiated into multiple shoots and shoot elongation respectively. (D) Rooting from regenerated shoot on MS half strength medium containing IAA $\left(0.5 \mathrm{mgl}^{-1}\right)$. (E) Hardened plantlets. 